\author{
Marquette University \\ e-Publications@Marquette
}

Biomedical Engineering Faculty Research and

Publications

Biomedical Engineering, Department of

$5-2017$

\title{
Assessment of Kinematics and Electromyography Following Arthroscopic Single-Tendon Rotator Cuff Repair
}

Jessica M. Fritz

Marquette University, jessica.fritz@marquette.edu

Ryan R. Inawat

Marquette University

Brooke A. Slavens

Marquette University, brooke.slavens@marquette.edu

John R. McGuire

Medical College of Wisconsin

Dean W. Ziegler

Blount Orthopaedic Clinic

See next page for additional authors

Follow this and additional works at: https://epublications.marquette.edu/bioengin_fac

Part of the Biomedical Engineering and Bioengineering Commons

\section{Recommended Citation}

Fritz, Jessica M.; Inawat, Ryan R.; Slavens, Brooke A.; McGuire, John R.; Ziegler, Dean W.; Tarima, Sergey S.; Grindel, Steven I.; and Harris, Gerald F., "Assessment of Kinematics and Electromyography Following Arthroscopic Single-Tendon Rotator Cuff Repair" (2017). Biomedical Engineering Faculty Research and Publications. 447.

https://epublications.marquette.edu/bioengin_fac/447 


\section{Authors}

Jessica M. Fritz, Ryan R. Inawat, Brooke A. Slavens, John R. McGuire, Dean W. Ziegler, Sergey S. Tarima, Steven I. Grindel, and Gerald F. Harris 


\title{
Assessment of Kinematics and Electromyography Following Arthroscopic Single-Tendon Rotator Cuff Repair
}

\author{
Jessica M. Fritz \\ Orthopaedic \& Rehabilitation Engineering Center, \\ Marquette University/The Medical College of Wisconsin, \\ Milwaukee, WI \\ Ryan R. I nawat \\ Orthopaedic \& Rehabilitation Engineering Center, \\ Marquette University/The Medical College of Wisconsin, \\ Milwaukee, WI \\ Brooke A. Slavens \\ Orthopaedic \& Rehabilitation Engineering Center, Marquette \\ University/The Medical College of Wisconsin \\ Milwaukee, WI \\ Department of Occupational Science \& Technology, University of \\ Wisconsin-Milwaukee \\ Milwaukee, WI
}




\author{
John R. McGuire \\ Department of Physical Medicine \& Rehabilitation, \\ The Medical College of Wisconsin, \\ Milwaukee, WI \\ Dean W. Ziegler \\ Blount Orthopaedic Clinic, \\ Milwaukee, WI \\ Sergey S. Tarima
}

\author{
Division of Biostatistics, The Medical College of Wisconsin, \\ Milwaukee, WI \\ Steven I. Grindel \\ Department of Orthopaedic Surgery, \\ The Medical College of Wisconsin, \\ Milwaukee, WI \\ Gerald F. Harris \\ Orthopaedic \& Rehabilitation Engineering Center, \\ Marquette University/The Medical College of Wisconsin, \\ Milwaukee, WI \\ Shriners Hospitals for Children, \\ Chicago, IL
}

\begin{abstract}
Background: The increasing demand for rotator cuff $(\mathrm{RC})$ repair patients to return to work as soon as they are physically able has led to exploration of when this is feasible. Current guidelines from our orthopedic surgery clinic recommend a return to work at 9 weeks postoperation. To more fully define capacity to return to work, the current study was conducted using a unique series of quantitative tools. To date, no study has combined 3-dimensional (3D) motion analysis with electromyography (EMG) assessment during activities of daily living (ADLs), including desk tasks, and commonly prescribed rehabilitation exercise.
\end{abstract}


NOT THE PUBLISHED VERSION; this is the author's final, peer-reviewed manuscript. The published version may be accessed by following the link in the citation at the bottom of the page.

Objective: To apply a quantitative, validated upper extremity model to assess the kinematics and muscle activity of the shoulder following repair of the supraspinatus RC tendon compared to that in healthy shoulders.

Design: A prospective, cross-sectional comparison study.

Setting: All participants were evaluated during a single session at the Medical College of Wisconsin Department of Orthopaedic Surgery's Motion Analysis Laboratory.

Participants: Ten participants who were 9-12 weeks post-operative repair of a supraspinatus RC tendon tear and 10 participants with healthy shoulders (HS) were evaluated.

Methods: All participants were evaluated with 3D motion analysis using a validated upper extremity model and synchronized EMG. Data from the 2 groups were compared using multivariate Hotelling $\mathrm{T}^{2}$ tests with post hoc analyses based on Welch t-tests.

Main Outcome Measurements: Participants' thoracic and thoracohumeral joint kinematics, temporal-spatial parameters, and RC muscle activity were measured by applying a quantitative upper extremity model during 10 activities of daily living and 3 rehabilitation exercises. These included tasks of hair combing, drinking, writing, computer mouse use, typing, calling, reaching to back pocket, pushing a door open, pulling a door closed, external rotation, internal rotation, and rowing.

Results: There were significant differences of the thoracohumeral joint motion in only a few of the tested tasks: comb maximal flexion angle ( $P$ $=.004)$, pull door internal/external rotation range of motion $(P=.020)$, reach abduction/adduction range of motion $(P=.001)$, reach flexion/extension range of motion $(P=.001)$, reach extension minimal angle $(P=.025)$, active external rotation maximal angle $(P=.012)$, and active external rotation minimal angle $(P=.004)$. The thorax showed significantly different kinematics of maximal flexion angle during the call $(P=.011)$, mouse ( $P$ $=.007)$, and drink tasks $(P=.005)$ between the 2 groups. The EMG data analysis showed significantly increased subscapularis activity in the RC repair group during active external rotation.

Conclusions: Although limited abduction was expected due to repair of the supraspinatus tendon, only a single ADL (reaching to back pocket) had a significantly reduced abduction range of motion. Thoracic motion was shown to be used as a compensatory strategy during seated ADLs. Less flexion of the thorax may create passive shoulder flexion at the thoracohumeral joint in efforts to avoid active flexion. The $\mathrm{RC}$ repair group participants were able to accomplish the ADLs within the same time frame and through thoracohumeral joint kinematics similar to those in the healthy shoulder group participants. In summary, this study presents a quantification of the effects of RC repair and rehabilitation on the ability to perform ADLs. It may also point to a need for increased rehabilitation focus on either regaining external rotation strength or range of motion following $\mathrm{RC}$ repair to enhance recovery and return to the workforce.

$P M \&$ R, Vol. 9, No. 5 (May 2017): pg. 464-476. DOI. This article is (c) Elsevier and permission has been granted for this version to appear in e-Publications@Marquette. Elsevier does not grant permission for this article to be further copied/distributed or hosted elsewhere without the express permission from Elsevier. 
NOT THE PUBLISHED VERSION; this is the author's final, peer-reviewed manuscript. The published version may be accessed by following the link in the citation at the bottom of the page.

\section{I ntroduction}

Rotator cuff $(\mathrm{RC})$ injuries and subsequent repairs often lead to missed work and altered upper extremity (UE) biomechanics when performing self-care and work-related activities of daily living (ADLs). Approximately 4.5 million people seek medical treatment for shoulder pain annually in the United States. $\stackrel{1}{-}$ Of these, RC injuries are among of the most common causes, with an estimated $250,000 \mathrm{RC}$ repair surgeries performed each year. 1 Because the prevalence of RC tears increases with age, the number of repair surgeries is estimated to increase as the workforce population ages. $\underline{1}$ The RC muscles (supraspinatus, infraspinatus, subscapularis, and teres minor) and associated tendons are integral to shoulder joint stabilization and

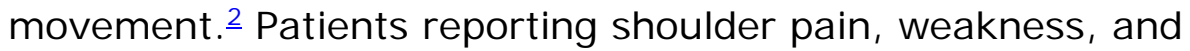
impingement often have tears in at least one RC tendon. $\frac{3}{-}$ Although RC tears can be asymptomatic, tears with pain and disability often require surgical repair. 4 The goal of repair for many is significantly decreased pain combined with regaining normal range of motion (ROM) to allow a return to the workforce. $\frac{1,2}{2}$ Normal recruitment of infraspinatus, supraspinatus, and teres minor muscles has been shown to return following repair of massive tears. $\frac{5}{}$ However, strength measurements of abduction and external rotation have indicated significantly reduced power in surgically treated shoulders compared with contralateral shoulders. 6

Following RC repair, the shoulder joint is commonly assessed through single ROM evaluation via goniometric and radiographic measures. $\frac{7,8}{}$ Goniometric measurements have shown return of ROM in passive and active flexion and abduction following $\mathrm{RC}$ repair. 9 Radiographic measures provide similar information, although they expose patients to ionizing radiation. Motion analysis techniques can provide a more thorough description of 3-dimensional (3D) kinematics and offer a noninvasive, dynamic, quantitative alternative to goniometric and radiographic methods. The use of motion capture to acquire UE kinematics is well established and has been applied in various populations including athletes, children with orthopedic disabilities, adults with shoulder pathology, and nonpathologic participants. $\underline{10}, \underline{11}, \underline{12}, \underline{13}, \underline{14}, \underline{15,16}$ The application of quantitative 3D motion analysis using a validated UE model with concurrent electromyography

PM \& R, Vol. 9, No. 5 (May 2017): pg. 464-476. DOI. This article is (C) Elsevier and permission has been granted for this version to appear in e-Publications@Marquette. Elsevier does not grant permission for this article to be further copied/distributed or hosted elsewhere without the express permission from Elsevier. 
(EMG) assessment may improve our understanding and approach to $\mathrm{RC}$ repair and rehabilitation. These methods can be directly applied to functional tasks such as ADLs and rehabilitation exercises. The current literature does not report the integrated use of 3D motion analysis with EMG toward examining the effects of $\mathrm{RC}$ repair on restoration of shoulder kinematics.

An established UE inverse dynamics model following the methods of Slavens et al was applied in the current study to examine shoulder kinematics, specifically at the thoracohumeral joint. 14, 15,16 The study population included 10 adult patients who underwent $\mathrm{RC}$ repair surgery and 10 adults with nonpathological (healthy) shoulders to gain a deeper understanding of typical thoracohumeral joint movement patterns of the shoulder complex. Kinematic and synchronized EMG data were analyzed during work-related and self-care ADLs and during rehabilitation exercises derived from physical therapy. Results address the differences between RC repair and healthy shoulder (HS) groups in their kinematic and EMG outcomes. We hypothesized that the RC repair groups would have kinematics and EMG activity similar to those in the HS group, thus supporting return to work activities in the RC repair group.

\section{Methods}

\section{Study Participants}

A total of 20 participants, 10 following $\mathrm{RC}$ repair and 10 with healthy shoulders, were recruited for this study. Each participant provided written informed consent to participate in the study approved by the Medical College of Wisconsin's Institutional Review Board. The $\mathrm{RC}$ repair group included 5 male and 5 female individuals with an average age of 53.9 years ( \pm 8.9 years) who had received arthroscopic supraspinatus tendon repair 9-12 weeks prior to their participation in the study (Table 1 ). All RC tears were $2 \mathrm{~cm}$ or less, measured in the anterior/posterior direction. A single surgeon performed all of the RC tear repairs. Participants were all undergoing postoperative RC repair physical therapy (PT) at the time of the study. The general guidelines for PT in this population consisted of passive ROM only to the shoulder for the first 6 weeks, then active ROM during

$P M \&$ R, Vol. 9, No. 5 (May 2017): pg. 464-476. DOI. This article is (c) Elsevier and permission has been granted for this version to appear in e-Publications@Marquette. Elsevier does not grant permission for this article to be further copied/distributed or hosted elsewhere without the express permission from Elsevier. 
weeks 6-8, then submaximal isometrics starting week 8, and initiation of progressive strengthening starting at week 10 (Table 2). Although the same rehabilitation protocol (Table 2) was provided to all patients for their therapist, the therapy was performed locally by the patients' preferred PT, and some progressed more quickly through their rehabilitation than others. Each participant had reached the point of isometrics in their PT by the time of the study. The HS group consisted of community volunteers with nonpathological shoulders, including 5 female and 5 male individuals with an average age of 22.8 years (SD 2.1). Absence of shoulder pathology was confirmed in the HS group through bilateral clinical ultrasound examination performed by a shoulder surgeon. Each participant underwent concurrent, synchronized motion and EMG analysis.

Table 1. RC repair group demographic characteristics and clinical tear metrics

\begin{tabular}{|c|c|c|c|c|c|c|}
\hline $\begin{array}{c}\text { RC Participant } \\
\text { No. }\end{array}$ & Gender & $\begin{array}{l}\text { Age } \\
(y)\end{array}$ & $\begin{array}{l}\text { Dominant } \\
\text { Side }\end{array}$ & $\begin{array}{l}\text { Surgical } \\
\text { Side }\end{array}$ & $\begin{array}{l}\text { Tear } \\
\text { Size }\end{array}$ & Tear Thickness \\
\hline 1 & $M$ & 67 & L & $\mathrm{R}$ & $\begin{array}{l}1.5-2 \\
\mathrm{~cm}\end{array}$ & Full-thickness \\
\hline 2 & $M$ & 62 & $\mathrm{R}$ & $\mathrm{L}$ & $\begin{array}{l}<1.5 \\
\mathrm{~cm}\end{array}$ & Full-thickness \\
\hline 3 & $M$ & 65 & $\mathrm{R}$ & $\mathrm{R}$ & $\begin{array}{l}1.5-2 \\
\mathrm{~cm}\end{array}$ & Full-thickness \\
\hline 4 & $\mathrm{~F}$ & 51 & $\mathrm{R}$ & $\mathrm{L}$ & $<1 \mathrm{~cm}$ & Full-thickness \\
\hline 5 & $M$ & 57 & $\mathrm{~L}$ & $\mathrm{~L}$ & $1 \mathrm{~cm}$ & 90\% Thickness \\
\hline 6 & $\mathrm{~F}$ & 45 & $\mathrm{R}$ & $\mathrm{L}$ & $<1 \mathrm{~cm}$ & Full-thickness \\
\hline 7 & $\mathrm{~F}$ & 56 & $\mathrm{R}$ & $\mathrm{R}$ & $1 \mathrm{~cm}$ & Full-thickness \\
\hline 8 & $\mathrm{~F}$ & 54 & $\mathrm{R}$ & $\mathrm{L}$ & $1.5 \mathrm{~cm}$ & Full-thickness \\
\hline 9 & $M$ & 41 & $\mathrm{R}$ & $\mathrm{R}$ & $<1 \mathrm{~cm}$ & Full-thickness \\
\hline 10 & $\mathrm{~F}$ & 41 & $\mathrm{R}$ & $\mathrm{L}$ & $1 \mathrm{~cm}$ & $\begin{array}{l}\text { Intrasubstance, significant } \\
\text { partial tear }\end{array}$ \\
\hline
\end{tabular}

All RC repair group participants underwent surgical repair to their supraspinatus tendon. Tear sizes were measured in the anterior/posterior direction.

$\mathrm{RC}=$ rotator cuff; $M=$ male; $F=$ female; $R=$ right; $L=$ left.

Table 2. Rehabilitation protocol provided to the therapist of each patient in the rotator cuff repair group following surgery

\section{Weeks 0-6}

Sling or immobilization to be worn at all times with ice pack to shoulder ( 20 minutes on; 20 minutes off)

Remove sling 4 or 5 times per day for gentle Codman/pendulum exercise ${ }^{*}$ (move body, not arm)

Active ROM to scapula, elbow, forearm, wrist, and hand starting 1 week postoperatively

Passive ROM in all planes with minimal goal by week 6 as follows:

Shoulder flexion, $90^{\circ}-100^{\circ}$

$P M \& R$, Vol. 9, No. 5 (May 2017): pg. 464-476. DOI. This article is (C) Elsevier and permission has been granted for this version to appear in e-Publications@Marquette. Elsevier does not grant permission for this article to be further copied/distributed or hosted elsewhere without the express permission from Elsevier. 
NOT THE PUBLISHED VERSION; this is the author's final, peer-reviewed manuscript. The published version may be accessed by following the link in the citation at the bottom of the page.

Abduction, $90^{\circ}-100^{\circ}$

Internal rotation, $60^{\circ}-75^{\circ}$

External rotation, $60^{\circ}-75^{\circ}$

(Note: These are minimal values; may increase to full passive ROM as tolerated)

Edema control

Postural education

Soft tissue mobilization

Monitor ROM to uninvolved joints (scapula, elbow forearm, wrist, and hand).

Home program: Codman/pendulum exercise*, active ROM to uninvolved joints, passive ROM to shoulder (by family member or closed chain)

Hot packs as needed; ultrasound (to muscle belly, not repair site)

\section{Weeks 6-8}

Continue passive ROM with goal of full ROM in all planes by week 8

Begin active ROM (with pulleys, cane, wall walks)

May use high-voltage pulsed current or transcutaneous electrical nerve stimulation as needed

Weeks 8-10

Gentle submaximal isometrics to affected shoulder in pain-free range

Active ROM to affected shoulder

Continue modalities and soft tissue mobilization as needed

Weeks 10+

Continue modalities and soft tissue mobilization as needed

Begin progressive resistance exercises with goal to meet preinjury status

Perform stretching as needed

Monitor scapular stability

ROM = range of motion.

*Codman/pendulum exercise is defined as the patient flexing the trunk and supporting the upper body with the uninvolved arm while the involved arm hangs free. The involved arm can be moved in a pendulum fashion by the trunk movement without active contraction of the shoulder muscles.

\section{Motion Capture System}

A Vicon (Vicon Motion Capture Systems, Ltd, Oxford, UK) motion capture system was used to quantify UE kinematics. The system included 14 infrared cameras and software for data acquisition and processing. Video data were collected at $120 \mathrm{~Hz}$. Following a gapfilling routine, which uses a cubic spline routine, kinematic data were processed through a Woltring filter with a predicted mean squared error (MSE) of $20-\mathrm{Hz}$ cutoff frequency. A Woltring filter is a quantic spline routine that smooths data in a manner similar to a double Butterworth filter. $\underline{17}$

PM \& R, Vol. 9, No. 5 (May 2017): pg. 464-476. DOI. This article is (C) Elsevier and permission has been granted for this version to appear in e-Publications@Marquette. Elsevier does not grant permission for this article to be further copied/distributed or hosted elsewhere without the express permission from Elsevier. 


\section{Upper Extremity Kinematic Model}

The validated UE model used for this study was based on methods by Slavens et al and consisted of the following 4 body segments: thorax, upper arm, forearm, and hand. $\underline{16}$ Segments were defined as rigid bodies using 11 reflective markers located on bony anatomical landmarks (Figure 1). The thorax and upper arm segment are connected by a 3-degree of freedom shoulder to determine thoracohumeral motion, which is a result of movement at both the scapulothoracic and glenohumeral joints. $\frac{15,16}{1}$ Thorax and thoracohumeral joint angles were determined through a Z-X-Y Euler rotation sequence to define motion in the sagittal, coronal, and transverse planes, respectively (Figure 1).$\underline{15,16}$ The thorax motions of flexion/extension, lateral bending, and axial rotation were assessed. $\underline{15}, \underline{16}, \underline{18,19}$ Thoracohumeral joint motions were determined applying the right hand rule from the rotation between the upper arm segment with respect to the thorax and included flexion/extension (sagittal plane), abduction/adduction (coronal plane), and internal/external rotation (transverse plane). $\underline{15}, \underline{16,20}$ The thorax segment motion was defined relative to the global coordinate system. The sagittal, coronal, and transverse plane motions are described through flexion(-)/extension(+), right $(+) /$ left $(-)$ lateral bending, and counterclockwise $(+)$ /clockwise $(-)$ axial rotation, respectively. Rotation directions are defined from the point of view of the subject where counterclockwise is rotation toward the left and clockwise is rotation toward the right. 19 The model was applied unilaterally on the surgical side for the $\mathrm{RC}$ repair group and the dominant side for the HS group. The 3D thorax and thoracohumeral joint angles were computed for kinematic analysis. 


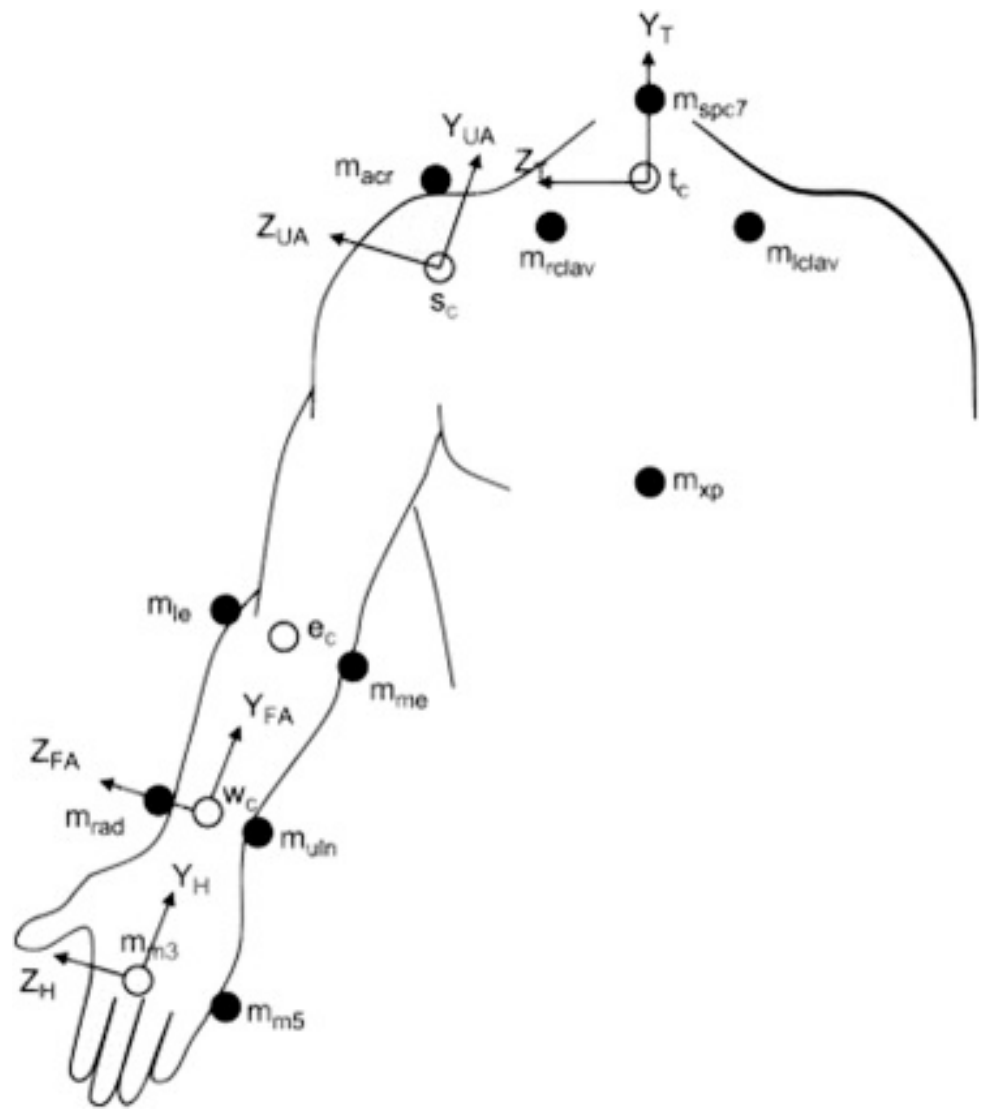

Figure 1. Upper extremity (UE) model marker set with joint centers and segmental coordinate systems. Referencing marker placement for the right UE body segments are defined as follows: Hand $(\mathrm{H})$ : The hand is defined by markers on the fifth metacarpal $\left(\mathrm{m}_{\mathrm{m} 5}\right)$, third metacarpal $\left(\mathrm{m}_{\mathrm{m} 3}\right)$, radial styloid process $\left(\mathrm{m}_{\mathrm{rad}}\right)$, and ulnar styloid process $\left(m_{\text {uln }}\right)$. Forearm (FA): The forearm is defined by the $m_{\text {rad }}$ and $m_{u l n}$ markers and markers on the medial epicondyle $\left(\mathrm{m}_{\mathrm{me}}\right)$ and lateral epicondyle $\left(\mathrm{m}_{\mathrm{le}}\right)$ of the humerus. Upper arm (UA): The arm segment is defined by the $m_{l e}$ and $m_{m e}$ markers, as well as a marker on the acromion $\left(m_{a c r}\right)$. Thorax $(T)$ : The thorax is defined by markers on $\mathrm{C7}$ spinous process $\left(\mathrm{m}_{\mathrm{spc} 7}\right)$, markers on the sternal extremity of the right clavicle $\left(m_{\text {rclav }}\right)$ and left clavicle $\left(m_{\text {Iclav }}\right)$, and a marker on the xiphoid process of the sternum $\left(m_{x p}\right)$. Reprinted from Slavens BA, Sturm PF, Harris GF. Upper extremity inverse dynamics model for crutch-assisted gait assessment. J Biomech 2010;43:2026-2031. Copyright 2010, with permission from Elsevier.

\section{Experimental Design}

Kinematic and EMG data were collected for all participants. Prior to analysis, each participant was instrumented for EMG assessment by a physical medicine and rehabilitation ( $P M \& R$ ) physician. The $P M \& R$ physician instrumented each participant with 3 fine-wire electrodes for the RC muscles. The participant's skin was numbed with cold spray before disposable paired fine-wire EMG needle electrodes (Chalgren 
Enterprises, Inc, Gilroy, CA) were inserted via ultrasound guidance into the subscapularis, supraspinatus, and infraspinatus muscles of the RC. The 2 wires were each attached to a metal contact of an electrode (Motion Lab Systems, Baton Rouge, LA) that was taped to the skin using hypoallergenic skin tape. The electrodes were connected to a Motion Lab Systems MA300 multi-channel EMG system backpack that was connected to the motion analysis system computer. Participants performed 3 maximal voluntary contraction (MVC) trials per RC muscle using a Biodex System 3 as a positioning device to isolate individual muscles while EMG signals were collected at $3000 \mathrm{~Hz}$. The position for each muscle isolation test was based on previous work describing isometric muscle testing. $\frac{21,22}{2}$ The MVC trials were performed with the participants instructed to contract their muscle as much as they could without causing any pain. For each participant, the gain was adjusted to obtain the optimal reading of each muscle. Once the gain was set, 3 trials were performed in each position. Electromyograms were fullwave rectified and filtered using an analog 8-pole, 0-phase Butterworth bandpass filter (150-1000 Hz). The EMG signals for each muscle were analyzed with the following steps: (1) full wave rectification of the signal; (2) calculation of the integral for every .02 seconds ( 60 samples) of data; (3) creation of a moving window that was 1 second wide; (4) calculation of the integral within that window; (5) summation of the fifty .02-second integrals; (6) location of the window with the maximal integral over 1 second; and (7) location of the average of the .02-second integrals within the maximal window. 22 A visual analog scale (VAS) was used to assess the participants' pain level during the MVC trials. Participants were asked to indicate their pain level on a scale from $0-10$, with 0 being no pain and 10 being the worst pain imaginable. $\underline{23}$ No participant exceeded a score of 2 on the VAS during testing.

Kinematics and EMG data of participants were collected and assessed for 10 ADL tasks. These tasks were chosen based on their commonality in adult work life, with adaptation from prior research. 11 This included 6 seated and 4 standing tasks (Table 3). For the seated ADLs, the participants sat in an armchair that had a fixed seat height of $48.3 \mathrm{~cm}$ with an arm height of $64.8 \mathrm{~cm}$. The seated tasks were performed at an adjustable-height table $(63.5-111.8 \mathrm{~cm})$ in the center of the camera capture volume. Table height was adjusted for comfort for each participant. An ADL was randomly chosen for the participant

$P M \&$ R, Vol. 9, No. 5 (May 2017): pg. 464-476. DOI. This article is (c) Elsevier and permission has been granted for this version to appear in e-Publications@Marquette. Elsevier does not grant permission for this article to be further copied/distributed or hosted elsewhere without the express permission from Elsevier. 
to perform, and the object corresponding to that ADL was placed on the desk. Participants were instructed to perform each task at a selfselected speed and to begin and end each task with their palms on the arms of the chair. When the participant was ready, motion capture was initiated, and the participant performed the task. Motion capture stopped when the participant returned their hands to the arms of the chair. This process was repeated for all seated tasks with a minimum of 3 trials per task. All trials for each task were completed before moving on to the next randomly selected task. The HS group performed all tasks with their dominant side. The RC repair group performed all tasks with their surgical side, unless the task relied on handedness and the surgery had been performed on their nondominant side. Six of the $\mathrm{RC}$ repair group participants did not perform the writing task because of handedness not corresponding with surgical side. It should also be noted that all participants wrote and typed their names. Differences in name length, letters used, and keyboard familiarity were not accounted for in the analyses. The procedure for the 4 standing ADLs was similar to that of the seated ADLs. For these tasks, participants were asked to start and end tasks with their arms at their sides, palms facing their legs. One participant did not perform the reach task because of ROM restrictions.

Table 3. Motion analysis procedures and thoracohumeral joint ROMs for ADLs and rehabilitation tasks

\begin{tabular}{|c|c|c|c|c|c|c|c|}
\hline & \multirow[t]{2}{*}{ Procedure } & \multicolumn{2}{|c|}{$\begin{array}{c}\text { Flexion/ Extension } \\
\text { ROM }\left({ }^{\circ}\right)\end{array}$} & \multicolumn{2}{|c|}{$\begin{array}{l}\text { Abduction/ Adduction } \\
\text { ROM }\left({ }^{\circ}\right)\end{array}$} & \multicolumn{2}{|c|}{$\begin{array}{l}\text { I nternal/ External } \\
\left.\text { Rotation ROM ( }{ }^{\circ}\right)\end{array}$} \\
\hline & & RC Group & $\begin{array}{c}\text { HS } \\
\text { Group }\end{array}$ & RC Group & HS Group & RC Group & HS Group \\
\hline \multicolumn{8}{|c|}{ ADL } \\
\hline Comb & $\begin{array}{l}\text { While } \\
\text { seated, } \\
\text { combed hair } \\
\text { or performed } \\
\text { combing } \\
\text { motion near } \\
\text { scalp with a } \\
\text { comb that } \\
\text { was provided }\end{array}$ & $\begin{array}{l}69.7 \\
(12.0)\end{array}$ & $\begin{array}{l}79.9 \\
(23.8)\end{array}$ & $31.6(22.2)$ & $27.5(8.0)$ & $\begin{array}{l}41.7 \\
(19.4)\end{array}$ & $44.9(20.1)$ \\
\hline Drink & $\begin{array}{l}\text { Drank water } \\
\text { from a } \\
\text { plastic, } \\
\text { handle-free } \\
\text { cup while }\end{array}$ & $\begin{array}{l}57.6 \\
(12.6)\end{array}$ & $\begin{array}{l}58.8 \\
(21.6)\end{array}$ & $22.1(12.4)$ & $21.6(10.9)$ & $\begin{array}{l}33.9 \\
(10.6)\end{array}$ & $42.3(26.9)$ \\
\hline
\end{tabular}

$P M \&$ R, Vol. 9, No. 5 (May 2017): pg. 464-476. DOI. This article is (c) Elsevier and permission has been granted for this version to appear in e-Publications@Marquette. Elsevier does not grant permission for this article to be further copied/distributed or hosted elsewhere without the express permission from Elsevier. 
NOT THE PUBLISHED VERSION; this is the author's final, peer-reviewed manuscript. The published version may be accessed by following the link in the citation at the bottom of the page.

\begin{tabular}{|c|c|c|c|c|c|c|c|}
\hline & \multirow[t]{2}{*}{ Procedure } & \multicolumn{2}{|c|}{$\begin{array}{c}\text { Flexion/ Extension } \\
\text { ROM }\left({ }^{\circ}\right)\end{array}$} & \multicolumn{2}{|c|}{$\begin{array}{c}\text { Abduction/ Adduction } \\
\text { ROM }\left({ }^{\circ}\right)\end{array}$} & \multicolumn{2}{|c|}{$\begin{array}{l}\text { I nternal/ External } \\
\text { Rotation ROM }\left({ }^{\circ}\right)\end{array}$} \\
\hline & & RC Group & $\begin{array}{c}\text { HS } \\
\text { Group }\end{array}$ & RC Group & HS Group & RC Group & HS Group \\
\hline & $\begin{array}{l}\text { seated at a } \\
\text { table }\end{array}$ & & & & & & \\
\hline Write & $\begin{array}{l}\text { Wrote name } \\
\text { using pen } \\
\text { and paper } \\
\text { while seated } \\
\text { at a table }\end{array}$ & $\begin{array}{l}37.3 \\
(11.5)\end{array}$ & $\begin{array}{l}35.9 \\
(15.8)\end{array}$ & $17.4(9.9)$ & $21.8(10.5)$ & $\begin{array}{l}27.7 \\
(11.0)\end{array}$ & $36.3(11.5)$ \\
\hline Mouse & $\begin{array}{l}\text { Moved } \\
\text { computer } \\
\text { mouse from } \\
\text { center to } \\
\text { top, far } \\
\text { corner of a } \\
\text { mouse pad }\end{array}$ & $\begin{array}{l}57.9 \\
(11.0)\end{array}$ & $\begin{array}{l}61.5 \\
(19.9)\end{array}$ & $21.5(7.9)$ & $22.7(9.3)$ & $\begin{array}{l}35.0 \\
(17.5)\end{array}$ & $40.2(28.7)$ \\
\hline Type & $\begin{array}{l}\text { Typed own } \\
\text { name on a } \\
\text { keyboard }\end{array}$ & $\begin{array}{l}52.2 \\
(12.4)\end{array}$ & $\begin{array}{l}54.7 \\
(15.8)\end{array}$ & $16.8(10.8)$ & $14.3(3.5)$ & $\begin{array}{l}40.2 \\
(22.5)\end{array}$ & $28.9(11.6)$ \\
\hline Call & $\begin{array}{l}\text { Picked up, } \\
\text { answered, } \\
\text { and replaced } \\
\text { mobile } \\
\text { phone while } \\
\text { seated at a } \\
\text { table }\end{array}$ & $\begin{array}{l}34.1 \\
(13.0)\end{array}$ & $\begin{array}{l}56.5 \\
(7.4)\end{array}$ & $14.7(6.6)$ & $28.6(4.2)$ & $\begin{array}{l}35.3 \\
(20.5)\end{array}$ & $46.8(18.6)$ \\
\hline Reach & $\begin{array}{l}\text { Reached to } \\
\text { back pocket } \\
\text { while } \\
\text { standing }\end{array}$ & $44.0(9.2)$ & $\begin{array}{l}45.6 \\
(8.8)\end{array}$ & $26.5(11.2)$ & $21.7(9.2)$ & $\begin{array}{l}51.9 \\
(16.6)\end{array}$ & $70.9(16.7)$ \\
\hline Light & $\begin{array}{l}\text { Flipped light } \\
\text { switch fixed } \\
\text { to a door } \\
\text { frame while } \\
\text { standing }\end{array}$ & $\begin{array}{l}54.6 \\
(12.6)\end{array}$ & $\begin{array}{l}53.4 \\
(10.8)\end{array}$ & $23.4(10.6)$ & $26.4(8.5)$ & $\begin{array}{l}63.4 \\
(22.6)\end{array}$ & $78.9(17.8)$ \\
\hline $\begin{array}{l}\text { Push } \\
\text { door }\end{array}$ & $\begin{array}{l}\text { Pushed open } \\
\text { a door fixed } \\
\text { to a door } \\
\text { frame with a } \\
\text { lever handle }\end{array}$ & $\begin{array}{l}40.8 \\
(10.5)\end{array}$ & $\begin{array}{l}36.9 \\
(14.9)\end{array}$ & $16.3(12.6)$ & $11.9(4.4)$ & $\begin{array}{l}28.5 \\
(10.2)\end{array}$ & $37.6(18.4)$ \\
\hline $\begin{array}{l}\text { Pull } \\
\text { door }\end{array}$ & $\begin{array}{l}\text { Pulled open } \\
\text { a door fixed } \\
\text { to a door } \\
\text { frame with a } \\
\text { lever handle }\end{array}$ & $\begin{array}{l}47.1 \\
(12.0)\end{array}$ & $\begin{array}{l}49.1 \\
(23.5)\end{array}$ & $27.5(9.7)$ & $22.2(12.4)$ & $\begin{array}{l}34.5 \\
(10.1)\end{array}$ & $38.4(21.8)$ \\
\hline
\end{tabular}

Rehabilitation motion

PM \& R, Vol. 9, No. 5 (May 2017): pg. 464-476. DOI. This article is (C) Elsevier and permission has been granted for this version to appear in e-Publications@Marquette. Elsevier does not grant permission for this article to be further copied/distributed or hosted elsewhere without the express permission from Elsevier. 
NOT THE PUBLISHED VERSION; this is the author's final, peer-reviewed manuscript. The published version may be accessed by following the link in the citation at the bottom of the page.

$\begin{array}{cccc}\begin{array}{c}\text { Procedure } \\ \text { ROM }\left({ }^{\circ}\right)\end{array} & \begin{array}{c}\text { Flexion/ Extension } \\ \text { RC Group } \begin{array}{c}\text { HS } \\ \text { Group }\end{array}\end{array} \text { RC Group HS Group } & \begin{array}{c}\text { Abduction/Adduction } \\ \text { ROM }\left({ }^{\circ}\right)\end{array} & \begin{array}{c}\text { Internal/ External } \\ \text { Rotation ROM }\left({ }^{\circ}\right)\end{array} \\ \text { RC Group HS Group }\end{array}$

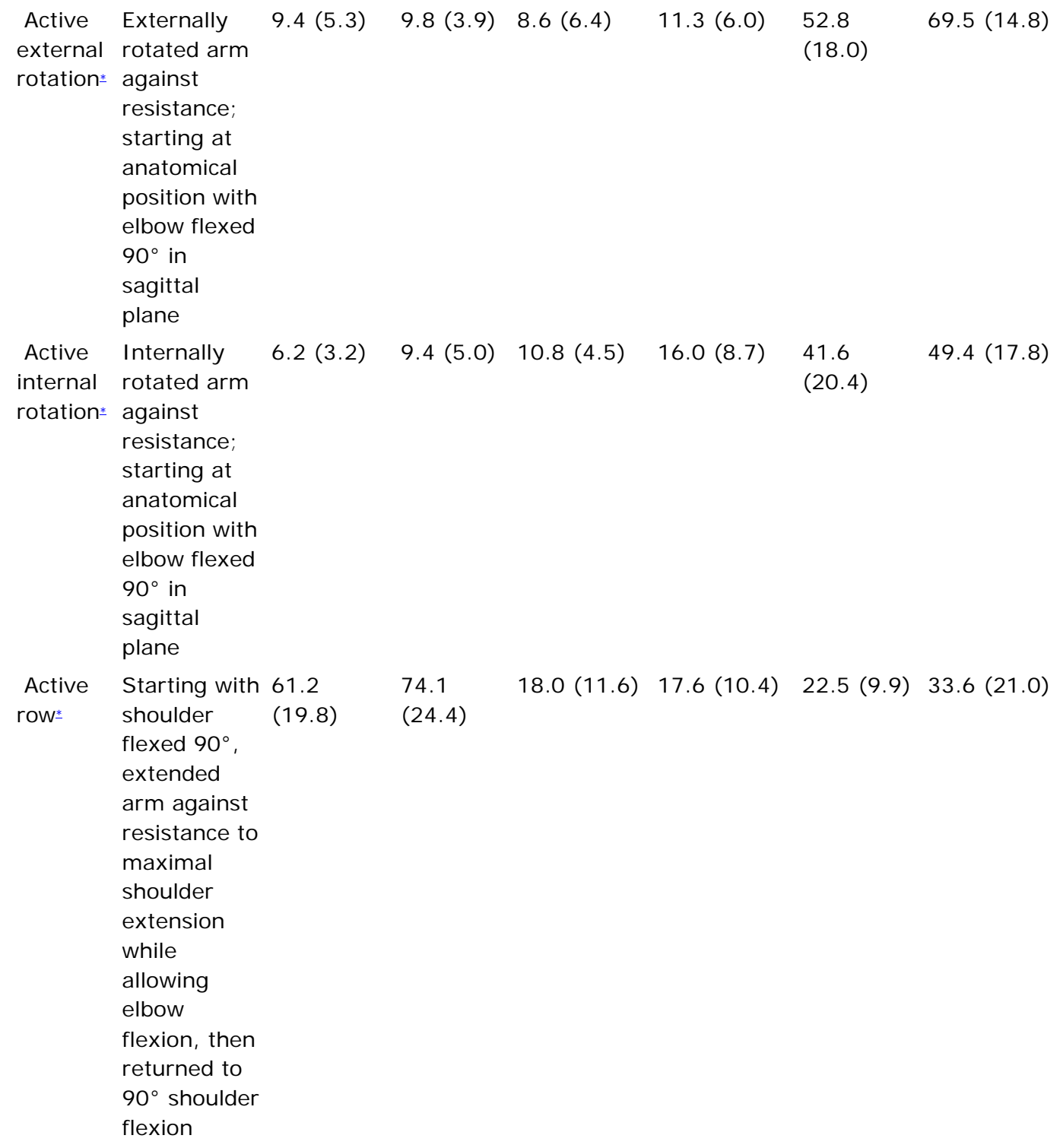

In addition to the 10 ADLs, 3 PT rehabilitation tasks were analyzed: internal rotation, external rotation, and rowing (Table 3). These tasks were based on the overall goals of the recommended PT 
protocol of increasing internal and external rotation as well as scapular stability following surgery. All tasks were performed passively and actively. The rehabilitation tasks were captured in a way similar to that of the standing ADLs. For passive tasks, the participant's arm was moved through the motion by an aide. Active tasks were performed against a resistance band held by a physician assistant (PA). The resistance was scaled by the PA for each participant to be at a level at which the participant could easily complete 10 repetitions. Two Therabands were used during this study, one light and one medium, with use determined by the PA and kept consistent within the participant group.

Kinematic values of minimal joint angle, maximal joint angle, and ROM (maximal joint angle minus minimal joint angle) in each plane (sagittal, coronal, and transverse) were calculated in MATLAB (MathWorks, Natick, MA) for the thorax and thoracohumeral joint. Temporal characteristics were also analyzed, including time to reach to the ADL object (start-to-object), time to perform the ADL from start to end time (task duration), and time to return to end position (object-toend). Task duration was also used to normalize task cycle as a percentage, with the start time point being $0 \%$ of the cycle and end time point being $100 \%$ of the cycle.

The EMG data collected during the ADL and PT tasks were analyzed to determine the percent MVC (\% MVC) that each RC muscle was active during each activity. For each task, the maximal value for each RC muscle was normalized to the muscle's MVC value and expressed as \% MVC.

\section{Statistical Analysis}

Multivariate Hotelling $\mathrm{T}^{2}$ tests with post hoc analyses based on Welch t-tests were performed to determine significant differences in kinematics between the RC repair and HS groups. This testing strategy was used to reduce the effect of multiple statistical tests on type 1 error. Three-dimensional Hotelling $\mathrm{T}^{2}$ tests were performed separately for minimal angle, maximal angle, and ROM of each task (Table 4). The Hotelling $\mathrm{T}^{2}$ test was used to compare each component of the 3D means (sagittal, coronal, and transverse planes) between the RC repair and HS groups.

$P M \& R$, Vol. 9, No. 5 (May 2017): pg. 464-476. DOI. This article is @ Elsevier and permission has been granted for this version to appear in e-Publications@Marquette. Elsevier does not grant permission for this article to be further copied/distributed or hosted elsewhere without the express permission from Elsevier. 
Table 4. Results of 3-dimensional Hotelling $\mathrm{T}^{2}$ tests, showing $\mathrm{P}$ values from comparisons of each component of the 3-dimensional means between the rotator cuff repair and healthy shoulder groups of the minimal and maximal angles and range of motion for each assessed task

Task

\begin{tabular}{lllllll} 
& \multicolumn{1}{c}{ Minimal } & Maximal & ROM & Minimal & Maximal & ROM \\
Comb & .466 & $.041^{*}$ & .525 & .124 & .054 & .143 \\
Drink & .322 & .356 & .629 & .177 & $.031^{*}$ & .382 \\
Type & .312 & .250 & .079 & .451 & .061 & .615 \\
Call & .612 & .417 & .966 & .418 & $.046 *$ & .164 \\
Mouse & .576 & .300 & .472 & .229 & $.036 *$ & .179 \\
Reach & $.049 *$ & .154 & $.001 *$ & .588 & .247 & .825 \\
Pull door & .241 & .215 & $.046 *$ & .418 & .303 & .385 \\
Push door & .198 & .795 & .505 & .924 & .434 & .113 \\
Light & .474 & .975 & .445 & .393 & .316 & .387 \\
Write & .978 & .871 & .895 & .283 & .227 & .870 \\
Passive internal rotation & .457 & .187 & .189 & .125 & .156 & .325 \\
Passive external rotation & .459 & .658 & .813 & .055 & .064 & .265 \\
Passive rows & .742 & .632 & .445 & .063 & $.015 *$ & .197 \\
Active internal rotation & .500 & .204 & .080 & .323 & .281 & .987 \\
Active external rotation & $.024 *$ & $.029 *$ & .096 & .648 & .451 & .521 \\
Active rows & .438 & .346 & .332 & .629 & .223 & .878
\end{tabular}

Both thoracohumeral and thoracic motions are presented.

$\mathrm{ROM}=$ range of motion.

*Significance at an a level of .050. (Significance from this test led to the task being assessed in all planes for differences between groups via Welch t-test. Details for each task are provided in Table 3.)

Post hoc Welch t-tests were performed only if the Hotelling $\mathrm{T}^{2}$ tests produced significant $P$ values (Table 5 ). Specifically, angles in the sagittal, coronal, and transverse planes were analyzed individually for each kinematic value tested. Temporal characteristics, including startto-object, task duration, and object-to-end, were compared between the groups in the same manner. Welch 2-tailed t-tests were performed on the EMG data to determine significant differences in \% MVC during the ADL and PT tasks. Significance was set at $\mathrm{P}<.050$.

Table 5. Values of significantly different kinematics of the thoracohumeral joint and thorax with their respective $P$ values from Welch $t$-tests

\section{RC Group \\ HS Group \\ $P$, Comparison}

\section{Thoracohumeral J oint}

Range of motion $\left({ }^{\circ}\right)$

$P M \&$ R, Vol. 9, No. 5 (May 2017): pg. 464-476. DOI. This article is (c) Elsevier and permission has been granted for this version to appear in e-Publications@Marquette. Elsevier does not grant permission for this article to be further copied/distributed or hosted elsewhere without the express permission from Elsevier. 
NOT THE PUBLISHED VERSION; this is the author's final, peer-reviewed manuscript. The published version may be accessed by following the link in the citation at the bottom of the page.

\begin{tabular}{|c|c|c|c|}
\hline & RC Group & HS Group & P, Comparison \\
\hline Pull door (internal/external rotation) & $51.9(16.6)$ & $70.9(16.7)$ & .020 \\
\hline Reach (abduction/adduction) & $14.7(6.6)$ & $28.6(4.2)$ & .001 \\
\hline Reach (flexion/extension) & $34.1(13.0)$ & $56.5(7.4)$ & .001 \\
\hline \multicolumn{4}{|l|}{ Maximal angle $\left({ }^{\circ}\right)$} \\
\hline Comb (flexion) & $96.2(12.2)$ & $116.6(14.5)$ & .004 \\
\hline Active external rotation (internal rotation) & $36.1(21.7)$ & $9.4(18.7)$ & .012 \\
\hline \multicolumn{4}{|l|}{ Minimal angle $\left({ }^{\circ}\right)$} \\
\hline Reach (extension) & $-7.6(14.7)$ & $-21.0(8.23)$ & .025 \\
\hline Active external rotation (external rotation) & $-5.5(21.0)$ & $-40.1(24.7)$ & .004 \\
\hline \multicolumn{4}{|c|}{ Thorax Segment } \\
\hline \multicolumn{4}{|l|}{ Maximal angle $\left({ }^{\circ}\right)$} \\
\hline Call (flexion) & $-17.1(10.3)$ & $-28.9(8.1)$ & .011 \\
\hline Drink (flexion) & $-16.5(11.2)$ & $-30.4(7.3)$ & .005 \\
\hline Mouse (flexion) & $-20.5(9.0)$ & $-32.5(7.7)$ & .007 \\
\hline Passive rows (lateral bending) & $-4.6(14.7)$ & $9.3(8.7)$ & .022 \\
\hline Passive rows (rotation) & $15.2(7.3)$ & $2.9(6.8)$ & .001 \\
\hline
\end{tabular}

\section{Results}

\section{Kinematics}

Thoracohumeral joint kinematics during ADLs and rehabilitation motions were analyzed, and significant differences were identified between the 2 groups. Statistically significant differences were seen in thoracohumeral kinematics during the comb, pull door, and reach ADL tasks as well as the rehabilitation task of active external rotation (Table 5, Figure 2). Post hoc Welch t-tests revealed which planes of motion were significantly different for the measured thoracohumeral kinematics of the 3 ADLs and the rehabilitation motion with $\mathrm{P}<.050$. The comb and pull door tasks were accomplished using a combination of flexion, external rotation, and abduction. The RC repair group showed a significantly decreased maximal flexion angle during the comb task, along with reduced rotational ROM during the pull door

PM \& R, Vol. 9, No. 5 (May 2017): pg. 464-476. DOI. This article is (C) Elsevier and permission has been granted for this version to appear in e-Publications@Marquette. Elsevier does not grant permission for this article to be further copied/distributed or hosted elsewhere without the express permission from Elsevier. 
task. Analysis of the reach task showed significantly reduced minimal extension, flexion/extension ROM, and abduction/adduction ROM in the $\mathrm{RC}$ repair group ( $\underline{\text { Table } 5}$ ). The active external rotation task showed significantly limited maximal and minimal external rotation angles in the $\mathrm{RC}$ repair group.
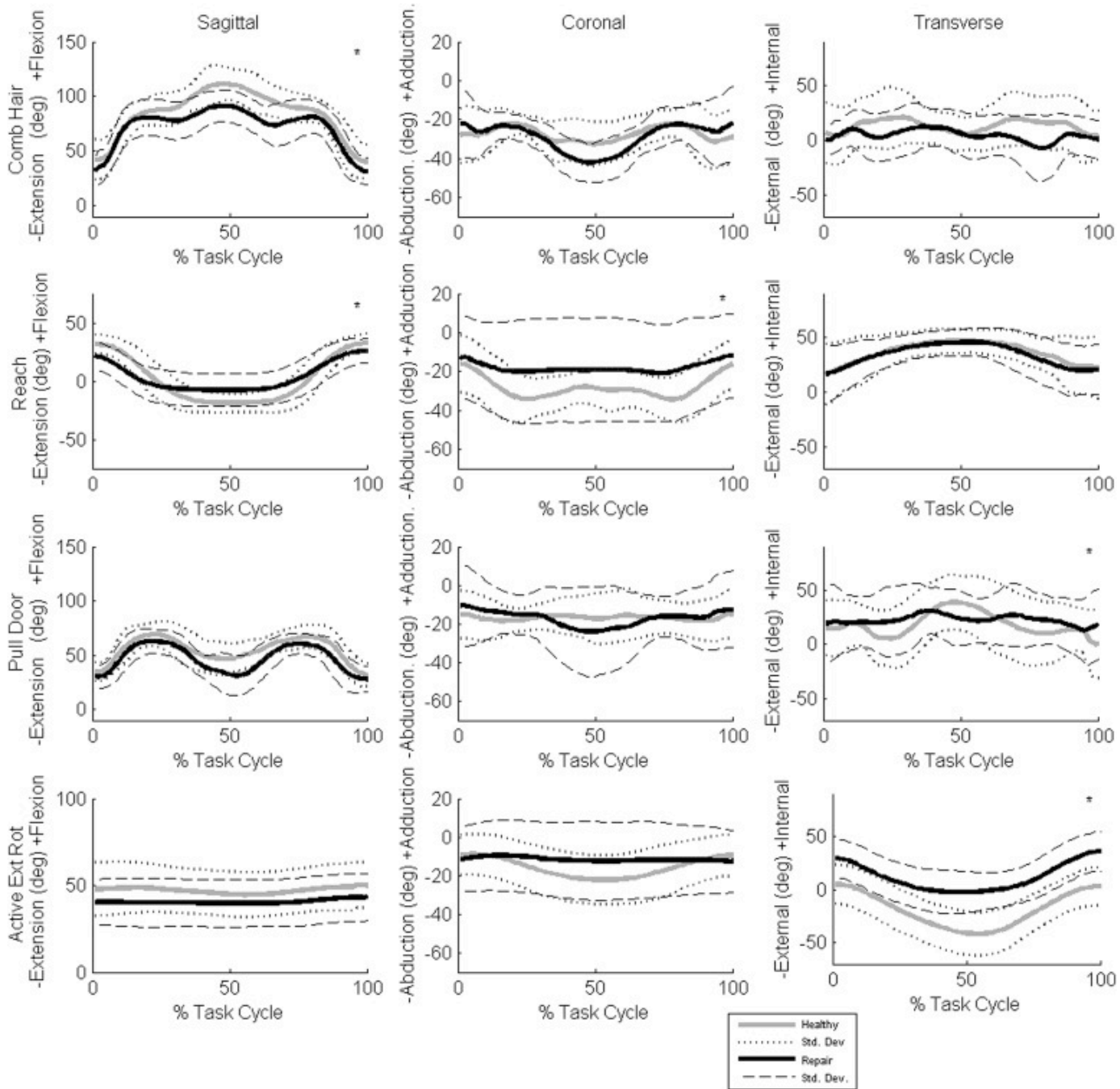

Figure 2. Thoracohumeral joint kinematics of the activities of daily living (ADLs) and rehabilitation tasks that showed significant differences between the rotator cuff (RC) repair and healthy shoulder groups. The tasks are defined by flexion/extension (sagittal plane), abduction/adduction (coronal plane), and internal/external rotation (transverse plane) over the duration of each task. The RC repair group means and standard deviations are represented by the solid black line and dashed black lines, respectively. Healthy shoulder (HS) group means and standard deviations are represented by the solid (mean) and dashed (standard deviation) gray lines. Asterisk $(*)$ indicates that the task's significant difference from the post hoc Welch t-test occurred in that plane. (See Table 2 for more details.) 
NOT THE PUBLISHED VERSION; this is the author's final, peer-reviewed manuscript. The published version may be accessed by following the link in the citation at the bottom of the page.

Of the 10 ADLs, only 3 displayed significantly different kinematics at the thorax (Table 5). Overall maximal thoracic flexion angles were significantly reduced in the $\mathrm{RC}$ repair group for the call, drink, and computer mouse ADL tasks. The RC repair group participants performed these tasks in a less flexed thoracic position than did the HS participants. Passive rowing demonstrated a significantly different lateral bending angle and a significantly increased counterclockwise axial rotation (toward the participant's left) angle in the $\mathrm{RC}$ repair group compared to the HS group.

\section{Temporal Characteristics}

Statistically significant differences of the temporal characteristics were seen only in the task durations of typing and passive internal rotation. However, neither one of these tasks was standardized. All other ADL and rehabilitation tasks showed no timing differences between the 2 groups.

\section{Electromyography}

The differences in \% MVC during the ADL and rehabilitation tasks were assessed between the RC and HS groups with a Welch t-test ( Table 6 ). The $\mathrm{RC}$ repair group showed a significantly higher average \% MVC in the subscapularis muscle during the active external rotation ( $P=.040,45.60 \%$ versus $19.49 \%)$, active row $(P=.001$, $48.9 \%$ versus $23.7 \%)$, and passive row $(P=.020,52.3 \%$ versus $18.6 \%$ ) tasks. The RC repair group also showed significantly higher \% MVC activation in the infraspinatus during the writing task ( $P$ $=.040,53.1 \%$ versus $7.1 \%)$. Although not significant at an a level of .050, the RC repair group demonstrated higher \% MVC values than the HS group in the 3 tested RC muscles during all tasks except the infraspinatus muscle during the active rows and reach tasks ( $\underline{\text { Table } 6}$ ).

PM \& R, Vol. 9, No. 5 (May 2017): pg. 464-476. DOI. This article is (C) Elsevier and permission has been granted for this version to appear in e-Publications@Marquette. Elsevier does not grant permission for this article to be further copied/distributed or hosted elsewhere without the express permission from Elsevier. 
Table 6. Electromyography \% MVC results comparison between RC repair and HS groups for the supraspinatus, infraspinatus, and subscapularis muscles during the ADL and rehabilitation tasks described in Table 3

Task

Supraspinatus \% MVC Infraspinatus \% MVC

\begin{tabular}{lllllllll}
\hline RC Group HS & $P$ & RC & HS & $P$ & RC & HS & $P$
\end{tabular}

Comb

Group

$41.5 \quad 34.8$

$(41.1) \quad(23.6)$

Drink

$44.2 \quad 29.7$

(57.3) (20.3)

Type

(79.9)

15.5

(79.9)

(11.9)

Call

$$
\text { (49.9) }
$$

26.2

Mouse

33.6

(43.7)

(17.2)

Reach

26.7

(38.3)

22.3

(13.8)

18.1

Pull door

35.6

(15.5)

(38.6)

23.2

Push door 33.

(38.7)

(22.9)

Light

31.8

24.3

(18.2)

(32.7)

17.4

Write

51.2

(22.0)

(55.8)

10.3

41.5

(9.8)

Passive

internal

rotation

Passive

external

rotation

Passive

rows

Active

(54.3)

9.4

(13.6)

$.660 \quad 34.4$

(40.8)

$.470 \quad 26.9$

(38.3)

$.240 \quad 24.3$

(32.5)

$.310 \quad 29.2$

(38.6)

$.450 \quad 28.0$

(35.5)

$410 \quad 3.0(2.7)$

$390 \quad 18.8$

(30.8)

$.490 \quad 25.0$

(41.6)

$.260 \quad 14.3$

(30.0)

$.160 \quad 53.1$

(41.3)

$.100 \quad 15.1$

(29.5)

18.1

(13.4)

.280

Group

$\begin{array}{lllll}10.2 & .230 & 64.6 & 39.4 & .210\end{array}$

(10.6)

(39.2)

$8.1(7.1) .170 \quad 52.3$

(36.1)

$8.8(9.3) .150 \quad 71.2$

(43.9)

$7.2(7.7) .110 \quad 49.2$

(42.1)

$\begin{array}{llll}11.2 & .150 & 33.4 & 26.3\end{array}$

(16.3)

(36.8)

(12.4)

$.580 \quad 53.6$

(32.7)

$18.8 \quad .690 \quad 55.5$

(20.0)

$5.7(5.4) .890$

(32.1)

63.9

(39.7)

$7.1(7.8) \quad .040 * \quad 47.4$

(43.7)

$3.7(3.6) \quad .270 \quad 41.0$

(35.2)

(18.8)

36.1

(25.7)

42.6

(28.6)

32.9

(37.1)

20.4

(19.4)

40.5

(54.7)

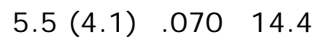

50.6

$8.6 \quad .090 \quad 15.0$

(70.5)

(12.7)

(28.9)

$7.3(7.0) \quad .060 \quad 14.0$

29.8

internal

(32.6)

(29.7)

$4.4(4.5) .330$

40.5

(34.3)

17.7
$(17.4)$

$5.4(5.2) \quad .350 \quad 52.3$

52.3
$(34.3)$

18.6

$\begin{array}{lll}7.0 & (8.7) & .510 \quad 59.7\end{array}$

(33.2)

34.4

(43.4)

Active

35.7

26.4

(29.9)

$\begin{array}{ll}510 & 24.8\end{array}$

18.4

(36.4)

(20.6)

$.650 \quad 45.6$

(31.5)

19.5

rotation

Active rows 41.7

19.7

.16021 .6

23.7

(35.0)

(20.5)

.75

(29.8)

48.9
$-49.7)$

(29.7)

23.7

(20.5)

MVC = maximal voluntary contraction; \%MVC = maximal value normalized to each muscle's MVC value throughout the task; $A D L=$ activity of daily living; $R C=$ rotator cuff; HS = healthy shoulder.

*Significant differences at a level of .050 as determined by Welch t-test.

\section{Discussion}

This study presents a unique application of a validated UE model for kinematic analysis integrated with EMG assessment. $\underline{16}$ The current

PM \& R, Vol. 9, No. 5 (May 2017): pg. 464-476. DOI. This article is (C) Elsevier and permission has been granted for this version to appear in e-Publications@Marquette. Elsevier does not grant permission for this article to be further copied/distributed or hosted elsewhere without the express permission from Elsevier. 
study focuses on thoracohumeral joint kinematics of the shoulder with concurrent fine-wire EMG analysis of the supraspinatus, infraspinatus, and subscapularis RC muscles. The supraspinatus muscle of the RC is primarily involved in thoracohumeral joint abduction, and has secondary actions at the thoracohumeral joint as an external rotator when the arm is abducted and as an internal rotator when the arm is flexed. $\stackrel{24}{ }$ Return of supraspinatus integrity following $\mathrm{RC}$ repair allows restoration of ROM in abduction, which is useful for many ADLs. This study examined 10 adult participants following $\mathrm{RC}$ repair and 10 young adults with healthy shoulders. The HS group was necessary to obtain a normal dataset of healthy kinematics. Our comparison group was selected and screened from a significantly younger population so as to avoid asymptomatic tears. Previous studies have shown a prevalence of asymptomatic tears in older populations. $\frac{25,26}{2}$ Hawkes et al performed a comparison of muscle activation between RC and healthy groups with an age difference similar to that in our groups. They reported a reorganization of strategies following RC tear, but no alteration to neuromuscular strategy following tear. $\underline{27}$ Subsequent work should include analysis of the full shoulder girdle musculature to assess the presence of reorganization strategies in muscular activity of RC patients both pre- and postoperatively.

The significantly different thoracohumeral joint kinematics found in this study show that motions other than those primarily controlled by the supraspinatus, such as flexion and external rotation, are affected by supraspinatus tear and subsequent repair. Previous studies have reported a reduction in external rotation and flexion following supraspinatus surgery. $\underline{28,29}$ Similar results were seen in the current study during the comb and active external rotation tasks (Table 5 ). Based on reported results by other researchers 29 and the results of the ADLs tested in this study, our RC repair group likely also had diminished range in completing upward reaching tasks, such as reaching at or above eye level, although our set of ADLs did not include this task. In addition to helping the deltoid to initiate shoulder abduction, the supraspinatus contributes to thoracohumeral joint stabilization by keeping the humeral head in contact with the glenoid fossa. Abnormal kinematics at this joint have been attributed to an altered contact position of the humerus against the glenoid fossa and displacement of associated shoulder ligaments due to RC tears and repairs. $\stackrel{7,30,31}{ }$ At 9-12 weeks following repair, our RC group showed 
limited thoracohumeral joint motion during tasks that required reaching overhead or behind (with thoracohumeral joint abduction) as well as during external rotation. This may be an indication of tightness in the joint's anterior capsule, external rotator weakness, or altered muscle activation and balance. Vidt et al reported a shift toward internal rotation while performing ADLs in older adults with RC tears. $\underline{29}$ This is purported to be a pain avoidance mechanism, especially when the infraspinatus is also torn. Although this was not observed in all of our tasks, our group was more homogenous in tear nature (Table 1) than the population tested by Vidt et al and had no infraspinatus injury involvement. The EMG analysis from this study supports the theory of improper muscle activation and balance through significantly higher \% MVC subscapularis activity in the RC repair group with active external rotation. Functionally, the subscapularis serves to internally rotate the humeral head when the humerus is at the side. Although we did not assess muscle force production, other researchers have shown that patients with an RC tear exhibit weak external rotator muscles. $\underline{29}$ This weakness may have been persisting following $\mathrm{RC}$ repair in our participants. The internal rotation shift during the external rotation task in the $\mathrm{RC}$ repair group could also be due to excessive activation from the deltoid and pectoralis major muscles. In RC patients, these muscles have been shown to increase activity as possible stabilizing and compensatory mechanisms following disruption of the normal coactivation stability control with the RC muscles. $\underline{27,29,32}$ The pull door task also showed less ROM in the RC, indicating a possible avoidance of rotational motion. However, this task did not show significantly different EMG activation between the 2 groups. Interestingly, the RC repair group demonstrated reduced extension and abduction range during the reach task compared with the HS group. Although not significant, this task and the active rows were the only tasks with a \% MVC (infraspinatus) trending lower in the RC repair group than the HS group.

Although it was not a focus of this study, we examined the temporal data from the EMG analysis during the active external rotation task for a representative participant from each population group. The active external rotation task was evaluated due to its significantly different kinematics in maximal and minimal rotation angles between the 2 groups. The representative participants were chosen based on their data's proximity to the population average. The

$P M \&$ R, Vol. 9, No. 5 (May 2017): pg. 464-476. DOI. This article is (c) Elsevier and permission has been granted for this version to appear in e-Publications@Marquette. Elsevier does not grant permission for this article to be further copied/distributed or hosted elsewhere without the express permission from Elsevier. 
HS participant exhibited an infraspinatus activation increase until maximal external rotation where it reached a level of $60 \%$ MVC, after which the activation level decreased to its resting value as the participant returned to the starting position. This specific HS participant showed minimal supraspinatus activation (maximum of $1.3 \%$ MVC) and a late peak of subscapularis activity (60\% MVC) with return to the starting position following maximal external rotation. In contrast, the RC participant displayed high supraspinatus (71\% MVC) and subscapularis (99\% MVC) activity throughout the task while producing nearly no infraspinatus activity (1.8\% MVC). The active external rotation task resulted in the same ROM between the 2 groups, but with a significant shift toward internal rotation for the $\mathrm{RC}$ repair group. In this particular task, RC repair group participants were able to externally rotate their humerus but did so with minimal infraspinatus activation. Although the representative RC participants performed the active external rotation task with a shifted position, they did so with RC muscle \% MVC and timing different from those of the representative HS participant. These results support the importance of an integrated EMG and kinematic data approach.

It is important to consider alternative effects on muscle activation when comparing data from these 2 groups. Even in the absence of pathology, the aging process commonly leads to muscle volume loss through diminished muscle fiber quantity and size (sarcopenia). Volume loss would lead to fewer contractile elements in an older population compared to a younger population such as our HS group. This could theoretically create higher \% MVC values during similar tasks. However, the data here only trends that way and does not show significant differences in \% MVC of the 3 tested RC muscles during the majority of the tasks performed, even if the task kinematics showed significant differences. A study by Aagaard et al looked at the estimated number of functioning motor units and MVC values in the tibialis anterior muscle between young and old age groups ( 27 and 66 years average age, respectively). The authors reported that although the number of motor units in the older age group was about $50 \%$ of that seen in the younger age group, they produced the same MVC $(\mathrm{Nm})$ values. 33 This gives us confidence in the few significant differences that we observed with larger subscapularis \% MVC during rows and active external rotation as well as the increased \% MVC of the infraspinatus during the reach task in the $\mathrm{RC}$ repair group compared to

$P M \&$ R, Vol. 9, No. 5 (May 2017): pg. 464-476. DOI. This article is (c) Elsevier and permission has been granted for this version to appear in e-Publications@Marquette. Elsevier does not grant permission for this article to be further copied/distributed or hosted elsewhere without the express permission from Elsevier. 
our HS group. In addition, Hawkes et al also performed an EMG analysis of RC patients with a massive tear versus healthy controls in populations of similar age differences. They reported no neuromuscular changes between their groups. $\stackrel{27}{ }$ Another contributing factor to muscle activation physiology in patients with chronic supraspinatus tears is the possibility of increased intramuscular fat content and clustering at the distal end of the muscle. $\frac{34}{4}$ This factor and tear size are both indicators of postoperative success and surgical indicators in our study population. Because our population consisted of full-thickness or near-full-thickness tears of the supraspinatus, these individuals would be at risk for intramuscular fat developing distally. $\frac{34,35}{}$ The single surgeon responsible for the repairs in the RC population did not observe fatty degeneration, and reported that tear sizes of $2 \mathrm{~cm}$ or less in the anterior/posterior direction (Table 1) were small enough to be repaired with minimal risk of postoperative failure. A recent review of the patients tested for this study showed that none of the repairs have failed 6-7 years postsurgery and that only one patient has developed a new RC tear.

The minimal number of significant differences found in the thoracohumeral joint and thorax kinematics between the RC repair and HS groups during ADLs and rehabilitation motions support restoration of functional ROM 9-12 weeks after supraspinatus tendon repair. This finding is in agreement with previous studies showing that the RC can return shoulder kinematics to normal ranges. $\underline{36}, \underline{37,38}$ Any activities that were significantly different were still capable of being performed by the majority of RC repair group participants, with one participant being unable to complete the reach task. Kolk et al reported that shoulder kinematics fully returned to normal at 1 year postrepair. ${ }^{39}$ Altered kinematic patterns in some of the ADLs and rehabilitation tasks observed in our participants may suggest compensatory motions in the $\mathrm{RC}$ repair group. In general, our $\mathrm{RC}$ repair group exhibited a similar, yet decreased, thoracohumeral joint flexion pattern while performing seated tasks (Figure 2). Future work should examine RC patients at intervals between 9 and 12 weeks postrepair, as was done in the immediate study, and 1 year postsurgery as done by Kolk et al. Intermittent assessment time points may better identify when shoulder kinematics fully return to normal following RC repair surgery. Full exploration of potential kinematic compensations should also

$P M \&$ R, Vol. 9, No. 5 (May 2017): pg. 464-476. DOI. This article is (c) Elsevier and permission has been granted for this version to appear in e-Publications@Marquette. Elsevier does not grant permission for this article to be further copied/distributed or hosted elsewhere without the express permission from Elsevier. 
examine the scapula, elbow, and wrist during ADL tasks such as hair combing.

The EMG analysis of the supraspinatus, infraspinatus, and subscapularis did not show significantly different \% MVC levels during any of the ADL tasks, with significantly different kinematic results. There was a significant increase in the \% MVC of the infraspinatus during the writing task. However, only 4 participants completed this task due to handedness. Although the other ADL tasks were not specific to dominant side, we further investigated this. We determined that some of the tasks such as the reach, call, comb, and drink tasks would likely be more comfortably performed with the dominant side. A comparison within the $\mathrm{RC}$ repair group for handedness effects did not reveal significant differences during the ADL tasks. However, the small study sample size limits the ability to discern differences within the RC repair group due to handedness and surgical side contributions to task performance. Future research should take this into account when establishing appropriate population sizes and functional tasks. Further work should also look at the remaining shoulder girdle muscles as well as the elbow and wrist to definitively determine compensatory patterns and mechanisms. The RC repair group showed significantly higher \% MVC subscapularis activation during the passive and active rows as well as active external rotation. Kinematics were also altered between the 2 groups during the active external rotation exercise. Although the subscapularis would not generally be required to perform these motions, as it is an internal rotator, it also serves as a stabilizer of the humeral head against anterior displacement. Its increased activation in the $\mathrm{RC}$ repair group during these rehabilitation tasks could indicate muscle tightness or an active tensing of the muscle to provide stability. The lack of differences between the 2 groups during passive external rotation indicate that the $\mathrm{RC}$ repair group has the ability to move through the exercise ranges, but may either lack strength or be activating inappropriate muscles to stabilize the shoulder and to prevent pain.

Reduced flexion of the thorax may have been used by the RC repair group to reduce the amount of thoracohumeral joint flexion required to move the hand upward to the desktop. This was demonstrated in the reduced flexion angles of the $\mathrm{RC}$ repair group during the call, drink, and computer mouse tasks. The participants are

$P M \& R$, Vol. 9, No. 5 (May 2017): pg. 464-476. DOI. This article is @ Elsevier and permission has been granted for this version to appear in e-Publications@Marquette. Elsevier does not grant permission for this article to be further copied/distributed or hosted elsewhere without the express permission from Elsevier. 
still in a position of a flexed thorax, but the $12^{\circ}$ of reduced flexion indicates that the RC population may be using a thorax compensatory strategy to reduce thoracohumeral flexion. Similar findings were reported in participants following shoulder replacement. 40

The $\mathrm{RC}$ repair participants were able to perform ADLs and rehabilitation tasks within a time frame similar to that of the HS participants. Restoration of temporal efficiency following surgery has also been reported by others who noted a return of range and quality of motion in ADLs following RC surgery. $\frac{41,42}{}$ Only the typing and passive internal rotation task durations showed any significant differences. However, the significant difference seen in time duration of the typing task is likely related to differences in average keyboard familiarity and proficiency between the 2 groups, as there was no difference in time from start to positioning their hands on the keyboard. All passive PT tasks were controlled by the study PA, so any temporal differences seen in those tasks would be due to cautionary movements with the $\mathrm{RC}$ repair group.

This study does have several limitations. Although it provides unique insight into 3D kinematics of the thorax and thoracohumeral joint as well as RC muscle activation levels between a group of RC repair patients and a HS population, scapula, elbow, and wrist kinematics were not analyzed. This information may provide further insight into compensation strategies used during ADLs and PT tasks. This study also did not analyze the remaining shoulder girdle muscles, including the fourth rotator cuff muscle, the teres minor. We recommend that future studies investigating compensation mechanisms include kinematics and muscle activation analysis of the full upper extremity. This study was also limited by the sample size of 20 participants. Part of the reason for the small sample size was to maintain a more homogenous group in terms of RC tear characteristics. Young healthy adults were recruited for comparison to assess ideal kinematics during the ADL and rehabilitation tasks. Therefore, future studies may consider also examining the contralateral limb along with the repaired shoulder and the HS population. Bilateral assessment of tasks should also consider effects of handedness. Without full knowledge of muscular compensatory strategies, and with the high variability of the small sample size,

$P M \&$ R, Vol. 9, No. 5 (May 2017): pg. 464-476. DOI. This article is (C) Elsevier and permission has been granted for this version to appear in e-Publications@Marquette. Elsevier does not grant permission for this article to be further copied/distributed or hosted elsewhere without the express permission from Elsevier. 
alterations to activities and therapy cannot be conclusively recommended for clinical practice.

\section{Conclusions}

Assessment of thoracohumeral joint kinematics in a population of 10 adults following single-tendon $\mathrm{RC}$ repair supports restoration of joint mobility for accomplishing many work-related ADLs. Although limited abduction was expected due to repair of the supraspinatus tendon, only a single ADL (reaching to back pocket) showed a significantly reduced abduction ROM. Thorax motion was shown to be used as a compensatory strategy during seated ADLs. Extending the thorax may create passive shoulder flexion at the thoracohumeral joint in efforts to avoid active flexion. $\mathrm{RC}$ repair participants were able to accomplish the ADLs within the same time frame and through similar thoracohumeral joint kinematics as the HS group participants. In summary, this study presents a quantification of the effects of RC repair and rehabilitation on the ability to perform ADLs. It may also point to a need for increased rehabilitation focus on either regaining external rotation strength or ROM following $\mathrm{RC}$ repair, to enhance recovery and return to the workforce.

\section{Acknowledgments}

This study was supported through the Medical College of Wisconsin Department of Orthopaedic Surgery intramural funding, by grant H133P080005 from the National Institute on Disability and Rehabilitation Research, and by grant UL1RR031973 from the Clinical and Translational Science Award (CTSA) program of the National Center for Research Resources and the National Center for Advancing Translational Science. Its contents are solely the responsibility of the authors and do not necessarily represent the official views of the National Institutes of Health. All grants contributed to this work solely through funding for supplies and personnel. The authors also thank Dr Leah Cobb for her work on the intramural proposal and Dara Mickschl for her assistance with participant testing.

$P M \& R$, Vol. 9, No. 5 (May 2017): pg. 464-476. DOI. This article is (C) Elsevier and permission has been granted for this version to appear in e-Publications@Marquette. Elsevier does not grant permission for this article to be further copied/distributed or hosted elsewhere without the express permission from Elsevier. 
NOT THE PUBLISHED VERSION; this is the author's final, peer-reviewed manuscript. The published version may be accessed by following the link in the citation at the bottom of the page.

\section{References}

${ }^{1}$ R.C. Mather 3rd, L. Koenig, D. Acevedo, et al. The societal and economic value of rotator cuff repair. J Bone J oint Surg Am, 95 (2013), pp. 1993-2000

2A. Day, N.F. Taylor, R.A. Green. The stabilizing role of the rotator cuff at the shoulder-responses to external perturbations. Clin Biomech, 27 (2012), pp. 551-556

3G.A.C. Murrell, J.R. Walton. Diagnosis of rotator cuff tears. Lancet, 357 (2001), pp. 769-770

${ }^{4}$ S. Tempelhof, S. Rupp, R. Seil. Age-related prevalence of rotator cuff tears in asymptomatic shoulders. J Shoulder Elbow Surg, 8 (1999), pp. 296299

${ }^{5}$ R.G. Hoellrich, S.I. Gasser, D.S. Morrison, P.R. Kurzweil. Electromyographic evaluation after primary repair of massive rotator cuff tears. J Shoulder Elbow Surg, 14 (2005), pp. 269-272

6S.K. Fokter, N. Cicak, J. Skorja. Functional and electromyographic results after open rotator cuff repair. Clin Orthop Relat Res (2003), pp. 121130

7M.J. Bey, C.D. Peltz, K. Ciarelli, et al. In vivo shoulder function after surgical repair of a torn rotator cuff: Glenohumeral joint mechanics, shoulder strength, clinical outcomes, and their interaction. Am J Sports Med, 39 (2011), pp. 2117-2129

${ }^{8}$ D. L. Riddle, J.M. Rothstein, R.L. Lamb. Goniometric reliability in a clinical setting: Shoulder measurements. Phys Ther, 67 (1987), pp. 668-673

9 D.R.M. Gore. Shoulder-muscle strength and range of motion following surgical repair of full-thickness rotator-cuff tears. J Bone J oint Surg Am, 68 (1986), pp. 266- 272

${ }^{10}$ G.S. Fleisig, B. Bolt, D. Fortenbaugh, K.E. Wilk, J.R. Andrews. Biomechanical comparison of baseball pitching and long-toss: Implications for training and rehabilitation. J Orthop Sports Phys Ther, 41 (2011), pp. 296-303

11 J.K. Gronley, C.J. Newsam, S.J. Mulroy, S.S. Rao, J. Perry, M. Helm. Electromyographic and kinematic analysis of the shoulder during four activities of daily living in men with C6 tetraplegia. J Rehabil Res Dev, 37 (2000), pp. 423-432

12L.M. Riek, P.M. Ludewig, D.A. Nawoczenski. Comparative shoulder kinematics during free standing, standing depression lifts and daily functional activities in persons with paraplegia: Considerations for shoulder health. Spinal Cord, 46 (2008), pp. 335-343

13.P.J. Rundquist, C. Obrecht, L. Woodruff. Three-dimensional shoulder kinematics to complete activities of daily living. Am J Phys Med Rehabil, 88 (2009), pp. 623-629

PM \& R, Vol. 9, No. 5 (May 2017): pg. 464-476. DOI. This article is (c) Elsevier and permission has been granted for this version to appear in e-Publications@Marquette. Elsevier does not grant permission for this article to be further copied/distributed or hosted elsewhere without the express permission from Elsevier. 
NOT THE PUBLISHED VERSION; this is the author's final, peer-reviewed manuscript. The published version may be

accessed by following the link in the citation at the bottom of the page.

${ }^{14}$ B.A. Slavens, N. Bhagchandani, M. Wang, P.A. Smith, G.F. Harris. An upper extremity inverse dynamics model for pediatric Lofstrand crutchassisted gait. J Biomech, 44 (2011), pp. 2162-2167

$\underline{15}$ B.A. Slavens, P.F. Sturm, R. Bajournaite, G.F. Harris. Upper extremity dynamics during Lofstrand crutch-assisted gait in children with myelomeningocele. Gait Posture, 30 (2009), pp. 511-517

$\underline{16}$ B.A. Slavens, P.F. Sturm, G.F. Harris. Upper extremity inverse dynamics model for crutch-assisted gait assessment. J Biomech, 43 (2010), pp. 2026- 2031

${ }^{17} \mathrm{H}$.J. Woltring. A FORTRAN package for generalized, cross-validatory spline smoothing and differentiation. Advanc Eng Softw, 8 (1986), pp. 104113

18G. Wu, F.C.T. van der Helm, H.E.J. Veeger, et al. ISB recommendation on definitions of joint coordinate systems of various joints for the reporting of human joint motion-part II: Shoulder, elbow, wrist and hand. J Biomech, 38 (2005), pp. 981-992

19 T.C. Nguyen, R. Baker. Two methods of calculating thorax kinematics in children with myelomeningocele. Clin Biomech, 19 (2004), pp. 1060 1065

${ }^{20}$ B. Hingtgen, J.R. McGuire, M. Wang, G.F. Harris. An upper extremity kinematic model for evaluation of hemiparetic stroke. J Biomech, 39 (2006), pp. 681-688

21F.A. Cordasco, I.N. Wolfe, M.E. Wootten, L.U. Bigliani. An electromyographic analysis of the shoulder during a medicine ball rehabilitation program. Am J Sports Med, 24 (1996), pp. 386-392

22 B.T. Kelly, R.J. Williams, F.A. Cordasco, et al. Differential patterns of muscle activation in patients with symptomatic and asymptomatic rotator cuff tears. J Shoulder Elbow Surg, 14 (2005), pp. 165-171

23 M.E. Wewers, N.K. Lowe. A critical review of visual analogue scales in the measurement of clinical phenomena. Res Nurs Health, 13 (1990), pp. 227- 236

${ }^{24}$ D.C. Ackland, M.G. Pandy. Moment arms of the shoulder muscles during axial rotation. J Orthop Res, 29 (2011), pp. 658-667

25 J.S. Sher, J.W. Uribe, A. Posada, B.J. Murphy, M.B. Zlatkin. Abnormal findings on magnetic resonance images of asymptomatic shoulders. J Bone Joint Surg Am, 77 (1995), pp. 10-15

${ }^{26}$ C. Pichonnaz, C. Duc, B.M. Jolles, K. Aminian, J.P. Bassin, A. Farron. Alteration and recovery of arm usage in daily activities after rotator cuff surgery. J Shoulder Elbow Surg, 24 (2015), pp. 1346-1352

27D.H. Hawkes, O. Alizadehkhaiyat, G.J. Kemp, A.C. Fisher, M.M. Roebuck, S.P. Frostick. Shoulder muscle activation and coordination in patients with a massive rotator cuff tear: An electromyographic study. J Orthop Res, 30 (2012), pp. 1140-1146

$P M \& R$, Vol. 9, No. 5 (May 2017): pg. 464-476. DOI. This article is (C) Elsevier and permission has been granted for this version to appear in e-Publications@Marquette. Elsevier does not grant permission for this article to be further copied/distributed or hosted elsewhere without the express permission from Elsevier. 
${ }^{28}$ R.A. McCabe, S.J. Nicholas, K.D. Montgomery, J J. Finneran, M.P. McHugh. The effect of rotator cuff tear size on shoulder strength and range of motion. J Orthop Sports Phys Ther, 35 (2005), pp. 130-135

$\underline{29}$ M.E. Vidt, A.C. Santago 2nd, A.P. Marsh, et al. The effects of a rotator cuff tear on activities of daily living in older adults: A kinematic analysis. J Biomech, 49 (2016), pp. 611-617

${ }^{30}$ C.-H. Wu, K.-V. Chang, P.-H. Su, W.-H. Kuo, W.-S. Chen, T.-G. Wang. Dynamic ultrasonography to evaluate coracoacromial ligament displacement during motion in shoulders with supraspinatus tendon tears. J Orthop Res, 30 (2012), pp. 1430-1434

31K. Yamaguchi, J.S. Sher, W.K. Andersen, et al. Glenohumeral motion in patients with rotator cuff tears: A comparison of asymptomatic and symptomatic shoulders. J Shoulder Elbow Surg, 9 (2000), pp. 6-11

32D.H. Hawkes, O. Alizadehkhaiyat, A.C. Fisher, G.J. Kemp, M. M. Roebuck, S.P. Frostick. Normal shoulder muscular activation and co-ordination during a shoulder elevation task based on activities of daily living: An electromyographic study. J Orthop Res, 30 (2012), pp. 53-60

33 P. Aagaard, C. Suetta, P. Caserotti, S.P. Magnusson, M. Kjær. Role of the nervous system in sarcopenia and muscle atrophy with aging: Strength training as a countermeasure. Scand J Med Sci Sports, 20 (2010), pp. 49-64

${ }^{34}$ A.C. Santago 2nd, M.E. Vidt, C.J. Tuohy, et al. Quantitative Analysis of three-dimensional distribution and clustering of intramuscular fat in muscles of the rotator cuff. Ann Biomed Eng, 44 (2015), pp. 21582167

35 H.M. Kim, N. Dahiya, S.A. Teefey, J.D. Keener, L.M. Galatz, K. Yamaguchi. Relationship of tear size and location to fatty degeneration of the rotator cuff. J Bone J oint Surg Am, 92 (2010), pp. 829-839

${ }^{36} \mathrm{~S}$. Moosmayer, G. Lund, U. Seljom, et al. Comparison between surgery and physiotherapy in the treatment of small and medium-sized tears of the rotator cuff: A randomised controlled study of 103 patients with oneyear follow-up. J Bone J oint Surg Am, 92-B (2010), pp. 83-91

37S. Namdari, A. Green. Range of motion limitation after rotator cuff repair. J Shoulder Elbow Surg, 19 (2010), pp. 290-296

38 j.C. Tauro. Stiffness and rotator cuff tears: Incidence, arthroscopic findings, and treatment results. Arthroscopy, 22 (2006), pp. 581-586

${ }^{39}$ A. Kolk, P.B. de Witte, J.F. Henseler, et al. Three-dimensional shoulder kinematics normalize after rotator cuff repair. J Shoulder Elbow Surg, 25 (2016), pp. 881-889

40M. Masjedi, C. Lovell, G.R. Johnson. Comparison of range of motion and function of subjects with reverse anatomy Bayley-Walker shoulder replacement with those of normal subjects. Hum Mov Sci, 30 (2011), pp. 1062-1071

PM \& R, Vol. 9, No. 5 (May 2017): pg. 464-476. DOI. This article is @ Elsevier and permission has been granted for this version to appear in e-Publications@Marquette. Elsevier does not grant permission for this article to be further copied/distributed or hosted elsewhere without the express permission from Elsevier. 
NOT THE PUBLISHED VERSION; this is the author's final, peer-reviewed manuscript. The published version may be accessed by following the link in the citation at the bottom of the page.

${ }^{41}$ R.H. Cofield, J. Parvizi, P.J. Hoffmeyer, W.L. Lanzer. Surgical repair of chronic rotator cuff tears: A prospective long-term study. J Bone J oint Surg Am, 83 (2001), pp. 71-77

42L.M. Galatz, C.M. Ball, S.A. Teefey, W.D. Middleton, K. Yamaguchi. The outcome and repair integrity of completely arthroscopically repaired large and massive rotator cuff tears. J Bone Joint Surg Am, 86 (2004), pp. 219-224

This study was supported through the Medical College of Wisconsin Department of Orthopaedic Surgery intramural funding, grant $\underline{\mathrm{H} 133 \mathrm{P} 080005}$ from the National Institute on Disability and Rehabilitation Research, and by grant UL1RR031973 from the Clinical and Translational Science Award (CTSA) program of the National Center for Research Resources and the National Center for Advancing Translational Science. 